\title{
Serviço Público, a quem serve? Uma trajetória marcada pela identificação com a loucura, a doença e a miséria no SUS
}

Teresa C ristina Endo

O dia estava particularmente quente e abafado, as salas de atendimento eram verdadeiras estufas, sem cortinas, e as janelas deixavam passar mais o barulho dos carros e sirenes do que algum ar fresco. O grupo estava marcado para as 13:30h, mas como sempre acontecia, os pacientes iam chegando aos poucos, instalando-se nos seus bancos de espera; alguns se esqueciam de entregar seus cartões na recepção e perdiam a entrada para o atendimento, permanecendo inertes durante a tarde toda, ainda aguardando serem chamados para o grupo das 13:30h.

Os profissionais chegavam aos poucos, sem pressa, poderiam ocupar a sala dos técnicos, composta de mesa, cadeiras e ar condicionado, que fora tão reivindicada nas reuniões de equipe como um lugar para as "trocas", para escrever nos prontuários, para alguma leitura, mas que nunca era usada, pois preferiam os espaços mais habitados nos quais as pessoas circulavam. E seguiam o ritual de todas as terças-feiras: alguns saíam à procura da chave da sala de grupo, sempre difícil de ser encontrada; outros iam em busca de mais cadeiras, ajudados pelos pacientes, e por vezes encontrava-se um ventilador disponível que ainda fazia sua função. 
O trabalho com o grupo iniciava-se, como de costume, por volta das 14:00h. Os pacientes eram chamados pelo nome inteiro inscrito nos seus cartões, mesmo que alguns ainda tentassem marcar uma proximidade: "Não me viu aqui, doutora, eu sou o Zé Nóia, esqueci o cartão, posso entrar no grupo?”

Os pacientes entravam na sala, que mal instalava as cadeiras e uma enorme mesa ao centro, acomodando-se um ao lado do outro, quase se tocando. O grupo era formado por onze homens, dependentes de álcool, moradores de albergue, duas psicólogas e uma estagiária de psicologia.

Naquele dia J. chegou atrasado; é alcoolista e mora em albergue, não é muito assíduo ao grupo, permanece quieto nas sessões. Pouco se conhece sobre sua história de vida; refere ter família no Nordeste, com a qual não tem contato "há mais de dez anos" (sic). Recolhe latinhas de cerveja e refrigerante para vender e sobrevive com os trocados que recebe dessa atividade. Apresenta-se sempre descuidado na sua higiene pessoal e aparência física, a ponto de os pacientes exprimirem repulsa ao seu intenso odor com caretas e comentários em voz baixa. Suas poucas falas se referem a pedido de carteira do SPtrans (isenção tarifária) e consulta com o médico clínico da unidade para receber vitaminas.

Foi a primeira e única vez que J. mostrou-se mais falante. Disse que fora agredido por um grupo de adolescentes que passava pelas redondezas e que pediulhe dinheiro; como ele não tinha nada amarraram-lhe os braços e pernas e injetaram-lhe tiner pelas narinas; demorou a ser socorrido pelos policiais que estavam próximos; segundo descreveu, não entendiam que ele precisava de ajuda. Foi levado para o pronto-socorro e ficou internado durante três dias.

Após o seu relato seguiu-se um grave silêncio, quebrado pela fala de um paciente, indagando e questionando-o sobre o local exato em que ocorrera o fato, pois referia: "Ali eu passo todos os dias e nunca me aconteceu nada, não deve ser ali, não, porque é uma rua que passa muita gente...”. Outro segue perguntando-lhe sobre o horário em que teria ocorrido a agressão: “Será que não era tarde da noite, companheiro? Se ficar ali de madrugada é problema, tem que saber se cuidar, eu não saio na rua depois de um certo horário...”. E outro ainda duvida de sua sobriedade: "Fala a verdade J., você devia ter tomado umas, confessa? Nem tinha condições de se defender, porque se é comigo eu não deixo esses meninos me atacarem... mas não pode beber J., tem que ficar esperto!”.

O paciente aprontava-se para se defender agora do segundo ataque - dos colegas de grupo - reafirmando o local, horário e a gratuidade da violência sofrida. Passava rapidamente da condição de vítima, na qual esperava ser acolhido em seu sofrimento, para a de culpado, merecedor, descuidado.

Esta fora a lógica construída nas ações de prevenção aos denominados grupos de risco, na época do advento da Aids. Isolou-se um grupo de pessoas que seria o alvo da doença, distanciando o resto da população do risco de contágio, 
isto é, a fórmula seria: se eu não pertencer ao grupo de risco, estarei protegido da Aids.

Os corpos, na apertada sala de grupo, espremiam-se num rearranjo de lugares, avolumavam-se num canto, como na composição de um time adversário, demarcando uma quase visível linha divisória que pretendia garantir uma distância, uma diferença, um isolamento de J. em sua condição de miserável.

Tentativas frustradas de escapar da impregnação da miséria, medo e odor, que naquele dia em especial se fazia mais penetrante em nossas narinas.

O movimento grupal era de visível hostilidade a um alvo aparentemente frágil. J. fez emergir ao grupo o horror à identificação com algo que lhes parecia próximo demais, um destino em comum. E todo esforço parecia ser o de rechaçar o indivíduo para afugentar a mesma “predestinação”, um porvir de desgraça, sofrimento e humilhação.

A maioria dos pacientes do grupo morava em albergue, tiveram suas famílias desestruturadas, estavam sozinhos e desempregados, foram abandonados, eram dependentes de álcool. Histórias de vida parecidas, condições sociais semelhantes e a mesma "identidade" de alcoolistas, elementos identificatórios que poderiam se constituir em ameaça de serem abatidos pelo mesmo fim. O medo de ser o que se é.

O relato do dia do enterro do pai de um outro paciente usuário de álcool, ilustra bem a convicção de que um castigo, uma retaliação o aguardaria. Relata que ninguém chorava no velório de seu pai; alguns contavam piadas, riam, não se aproximavam do caixão e ouvia os comentários: “Já vai tarde, isso que deu, foi procurar... seu destino não poderia ser outro, uma vida de vagabundagem, sem pensar nos filhos, na mulher... foi bem merecido... agora deixou o filho, filho de peixe peixinho é...”

Seria apaziguador conceber o profissional de saúde imune a esse processo identificatório (afinal, o que isso tem a ver comigo?), e distante da passagem ao ato da retaliação sobre os pacientes.

A identificação com a miséria não está restrita aos pacientes, a precariedade dos serviços pode ser percebida nas paredes “incandescentes” da instituição ou na atenção dispensada pelos profissionais. Os atrasos nos atendimentos, a morosidade do tratamento, o clima de letargia e a insistente repetição das mesmas práticas revelam formas (nem tão) veladas de expulsão dos pacientes, principalmente quando a miséria se mostra sem maquiagem.

A cena do paciente mal-cheiroso ao relatar a agressão que sofreu assemelhase a uma outra, de rua, de um menino pedinte, encoberto por sujeira, fuligem, poluição e um cobertor surrado, de pés no chão. Os motoristas abordados tinham entre si a mesma reação de susto, medo, repulsa. É como se o pedinte não pudesse apresentar-se em toda sua miséria, aos olhos do caridoso motorista. 


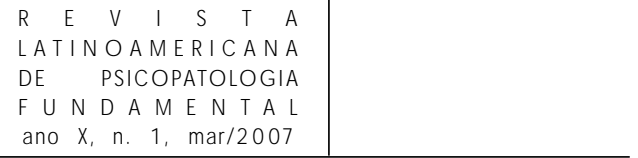

A ostentação da pobreza é a "propaganda" do pedinte, que pretende provocar pena, comiseração e até culpa em outrem. No entanto, a extrema miséria parece ter o efeito contrário, destitui o miserável de sua humanidade, impossibilitando a identificação com o outro: "Eu poderia ser você ou seu filho!".

Nos Hospitais Psiquiátricos há cerca de vinte anos era comum o cenário de pacientes descalços, sem roupas íntimas e absorventes higiênicos, impedidos de portar objetos pessoais, vestindo camisolões de hospital com carimbo de identificação da instituição. Os pacientes, desse modo, eram facilmente identificados. Não havia o menor risco de serem confundidos com visitantes, familiares ou profissionais. Na realidade, muitas vezes era difícil reconhecer-lhes a humanidade, o gênero, a idade sob o manto da impregnação medicamentosa e dos (ul)trajes da loucura.

São "casos" como estes que, às vezes, conseguem acessar o serviço público e mobilizam toda a equipe de saúde, mesmo antes de se saber a que veio o paciente. São pessoas que incomodam mais pela revelação da miséria do que pelo sofrimento psíquico que apresentam.

O sus (Sistema Único de Saúde) foi criado para favorecer o acesso da população às diversas unidades de saúde. Porém, as mensagens dirigidas à população são ambíguas: ora de inclusão, ora de expulsão e exclusão.

Em um hospital público de periferia, recém-inaugurado, notou-se que a população demorava a ingressar no serviço. Foram meses até o hospital ser reconhecido pelos pacientes como local de atendimento público. O depoimento deles revelava a concepção de que era tão novo e bonito que só poderia ser "hospital para rico!".

Essa seleção “natural” da clientela que deve acessar o sUS ocorre, diariamente, nas unidades de saúde públicas. É essa população, submetida ao exílio social, que dificilmente acessa os serviços de saúde, que deveria ter prioridade nos atendimentos. Testemunhamos uma prática de atenção à saúde, distante do modelo de universalidade proposto pelo SUS, em que o acesso aos miseráveis está cada vez mais restrito, temido e evitado.

Todo cidadão tem acesso livre aos serviços de saúde pública sem precisar mostrar identidade, carteira de trabalho, comprovante de residência. No entanto, parecem ser ativados mecanismos de resistência, desde a porta de entrada, ao ingresso da população.

Não é raro encontrarmos guardas espalhados pelos corredores dos ambulatórios, na recepção, que na realidade vão compondo o cenário da saúde. O atendimento à saúde parece estar se tornando, cada vez mais, "caso de polícia”.

O profissional que ingressa no serviço público, não raro sustenta e idealiza um modelo mais conhecido de atendimento clínico, o de consultório particular 
ou o de clínica-escola, com as particularidades e preocupações éticas e estéticas daquele contexto: Cadê minha sala, cadê meu supervisor?

Ao plantar os pés numa instituição de saúde pública, perde os referenciais de atuação e, o mais grave, de reflexão sobre sua prática. Vê-se "impactado" frente à realidade com a qual se depara, imobiliza-se diante do paciente miserável e pode manter-se na paralisia durante muito tempo. Impossibilitado de pensar, mimetiza em sua práxis o funcionamento patológico da instituição em que está inserido.

Tal como o paciente que não se identifica com o hospital para rico, a identificação com a miséria pode ser igualmente revelada nos profissionais que exercem uma prática empobrecida de envolvimento, de estímulo, de novidade e de reflexão sobre esse ofício tão interdependente do encontro com sua própria "miséria humana”; um trabalho, literalmente, visceral. 